\title{
A Practical and Safe Optimization Method for Temporary Cable Layout on the Upper Beam of Beam-Arch Composite Rigid Frame Bridge
}

\author{
Yanchao Ding ${ }^{1 *}$, Zhongfu Xiang ${ }^{1}$, Yayong Li $^{2}$, Xuesong Zhang ${ }^{1}$, Yin Zhou ${ }^{1}$ \\ ${ }^{1}$ School of Civil Engineering, Chongqing Jiaotong University, Chongqing 400074, China \\ ${ }^{2}$ China Construction Tunnel Corp., Ltd, Chongqing 401320, China
}

Corresponding Author Email: dingyc@mails.cqjtu.edu.cn

https://doi.org/10.18280/ijsse.100112

Received: 15 June 2019

Accepted: 27 October 2019

\section{Keywords:}

beam-arch composite rigid frame, upper beam, cable layout, cable force optimization, structural safety

\begin{abstract}
Long-span beam-arch composite rigid frame is a novel type of bridge structure. The safe operation of this bridge mainly depends on the bearing capacity of the root section of the upper beam. The upper beam is often constructed by the cantilever method using temporary cables (cable-stayed cantilever method). If the cable layout and cable forces are not reasonable, a plastic hinge will gradually form the root section of the upper beam under the unfavorable internal forces, posing a severe threat to the bridge safety. Therefore, this paper mainly aims to optimize the layout of temporary cables for the implementation of cable-stayed cantilever method. Firstly, the authors explored the essential function of the temporary cables on the upper beam. Next, four different methods for cable force optimization were compared, and the optimal method was identified for the upper beam of long-span beam-arch composite rigid frame bridge. Finally, 78 groups of temporary cable layouts were compared to find the optimal pattern. The results show that the essential function of the temporary cables on the upper beam is to reduce the negative bending moment on the root section of the upper beam at the completion state; the optimal method for cable force optimization is to tension the $\mathrm{j}$-th temporary cable to the tensile stress on the lower edge of the upper beam; it is recommended to tension five temporary cables during the implementation of cable-stayed cantilever method. The research results provide new insights into the safety enhancement of beam-arch composite rigid frame bridges.
\end{abstract}

\section{INTRODUCTION}

Being the combined result of continuous rigid frame bridge and arch bridge [1], long-span beam-arch composite rigid frame is a novel bridge structure with excellent mechanical properties. In this structure, the concrete is removed from the web at the root of the main beam [2]. The removal not only reduces the consumption of concrete, but also overcomes a safety hazard of conventional continuous rigid frame bridge: the severe down-warping at the mid-span in the long run.

Considering the unique structure, the long-span beam-arch composite rigid frame bridge must be constructed separately in the upper beam and the lower arch. In general, the lower arch can be built by the cantilever method using temporary cables (the cable-stayed cantilever method), while the upper beam can be set up by either the cable-stayed cantilever method or the cantilever method using a cast-in-situ support on the lower arch (the supported cantilever method). During the cantilever casting of the upper beam/lower arch, the tensile stresses at the upper and lower edges of the section must be controlled below the designed tensile strength of the concrete.

The above construction methods have been widely adopted in mainly bridges across China. For example, Beipanjiang Bridge (main span: 290m) [3], a super large bridge on Shuicheng-Panxian Expressway, was constructed by the cable-stayed cantilever method in the lower arch and the supported cantilever method in the upper beam (hereinafter referred to as Construction Method 1). Meanwhile, Lijia
Jianglingjiang Bridge (main span: 245m), a super large bridge in Chongqing, was constructed by cable-stayed cantilever method in both the upper beam and lower arch (hereinafter referred to as Construction Method 2) [4]. The two construction methods are explained in Figures 1 and 2, respectively. Construction Method 1 is suitable for open-web rigid frame bridge with a highly stiff lower arch and a short open-web area. Construction Method 2 applies to beam-arch composite rigid frame bridge with a low-stiffness lower arch and a long open-web area. The latter method is more applicable than the former one, because of the ability to adjust the internal force distribution of the upper beam.

In this paper, Lijia Jianglingjiang Bridge (Figure 3), which was built by Construction Method 2, is taken as the engineering background. The safety of the bridge structure is mainly controlled by the bearing capacity of the upper beam, rather than that of the lower arch. If the cable layout and cable forces are not reasonable on the upper beam [5], the root section of the upper beam will enter the plastic state early in the operation phase. The resulting plastic hinge will weaken the bearing capacity of the bridge. To ensure the safe operation of the bridge, it is necessary to develop a simple and practical strategy to optimize the cable layout and cable forces on the upper beam, and keep the internal forces in the optimal distribution at the completion state.

Many scholars have attempted to optimize the cable forces of different types of bridges. The optimization is very complex for cable-stayed bridge. For Lijia Jianglingjiang Bridge, the 
cable force optimization on the upper beam is similar to that of cable-stayed bridge. The main research results on cable force optimization of bridges are as follows: In 2003, Liang et al. [6] developed a practical method for cable force optimization of the cable-stayed bridge at the completion state, in which the main beam stiffness is reduced by 1,000 times based on the theory of minimum bending energy, and the cable forces at the completion state is optimized under the principle of impact matrix. In 2007, Qi et al. [7] adjusted the cable forces to minimize the bending moment of the section of the arch ring at the completion state, and thus optimized the force of each cable before the closure of a cantilever casted arch bridge, achieving the desired internal force distribution at completion state. In 2012, Hassan et al. [8] combined finite-element analysis and B-spline curves into a novel approach to optimize the post-tensioning cable forces under the dead load of the final configuration of the bridge.

In 2015, Martins et al. [9] presented an entropy-based approach for cable force optimization on concrete cable-stayed bridge, which fully considers the impacts of construction sequence and concrete shrinkage and creep on cable forces at completion state. In 2015, He et al. [10] optimized the cable forces in cantilever casting of a deck arch concrete bridge (main span: $189.9 \mathrm{~m}$ ), with the overall stress of the arch ring as the objective function. In 2016, Hu et al. [11] analyzed the whole process of the cable-stayed cantilever method for the main arch of long-span reinforced concrete arch bridge, solved the cable forces by the zero bending moment method, and adopted the impact matrix to optimize the cable forces under the maximum span of the cantilever, with arch ring bending energy as the objective function. In 2017, Zarbaf et al. [12] proposed an estimation method for cable forces of cablestayed bridge, using the genetic algorithm (GA0 and particle swarm optimization (PSO).

In 2017, Gao el al. [13] designed an optimization method for the minimum cost design of a pre-stressed concrete cablestayed bridge; the number of pre-stressed tendons in the beam, the cable forces of the beam and pylon, the cable size and section area were taken as the design variables, and the stress and displacement constraints were applied to ensure the safe use of the bridge structure. In 2018, Ha et al. [14] created an effective optimization method for cables of steel cable-stayed bridge, with the aid of nonlinear inelastic analysis and a micro GA; the main innovation lies in the optimization of initial tension and total weight of the cables. In 2018, Song et al. [15] put forward a counterweight-based optimization method for cable forces of long-span asymmetric cable-stayed bridge, which optimizes the cable forces through the variable step search of design variables like cable forces, load, and counterweight range. In 2019, Arellano et al. [16] proposed a multi-objective approach to optimize the cable overlap length in multi-span cable-stayed bridge; the objectives include cable cost, pylon top displacement and alternate live load. In 2019, Dai et al. [17] summed up the features, applicable ranges and limitations of cable force optimization strategies for cablestayed bridge, and predicted the trend in cable force optimization.

Drawing on the relevant studies on cable force optimization, this paper proposes a practical optimization method for the temporary cables on the upper beam in beam-arch composite rigid frame bridge. The proposed method aims to control the upper and lower tensile stresses below the designed tensile strength of concrete, and ensure the uniform distribution of cable forces. The research results provide a simple and efficient approach for cable force optimization.

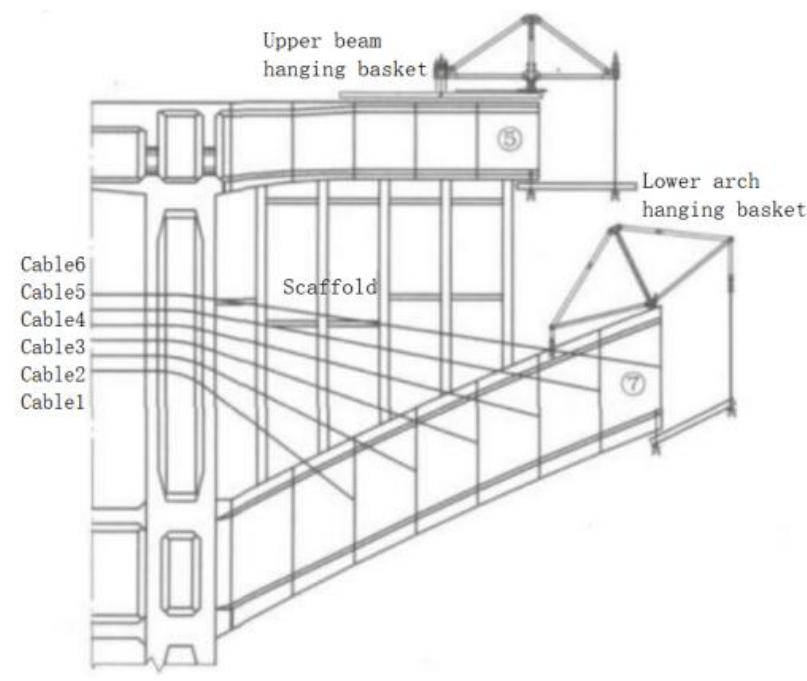

Figure 1. Construction Method 1

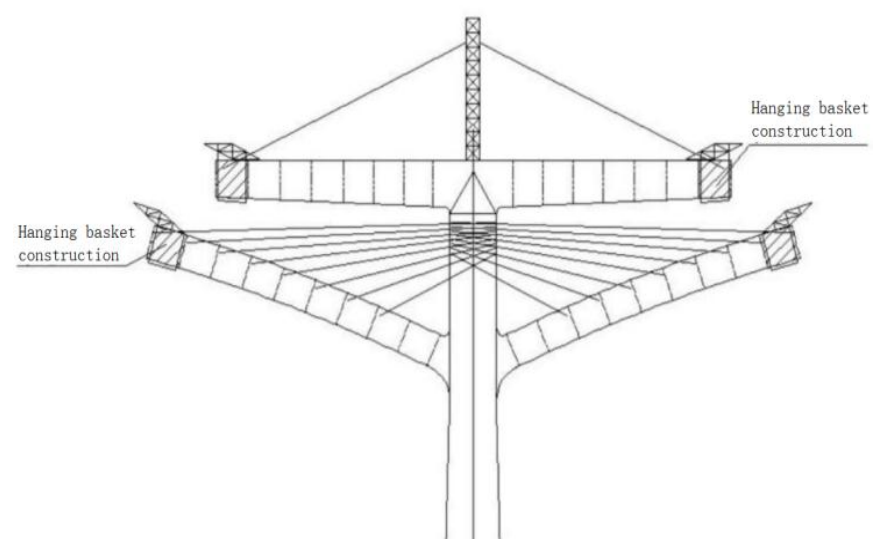

Figure 2. Construction Method 2

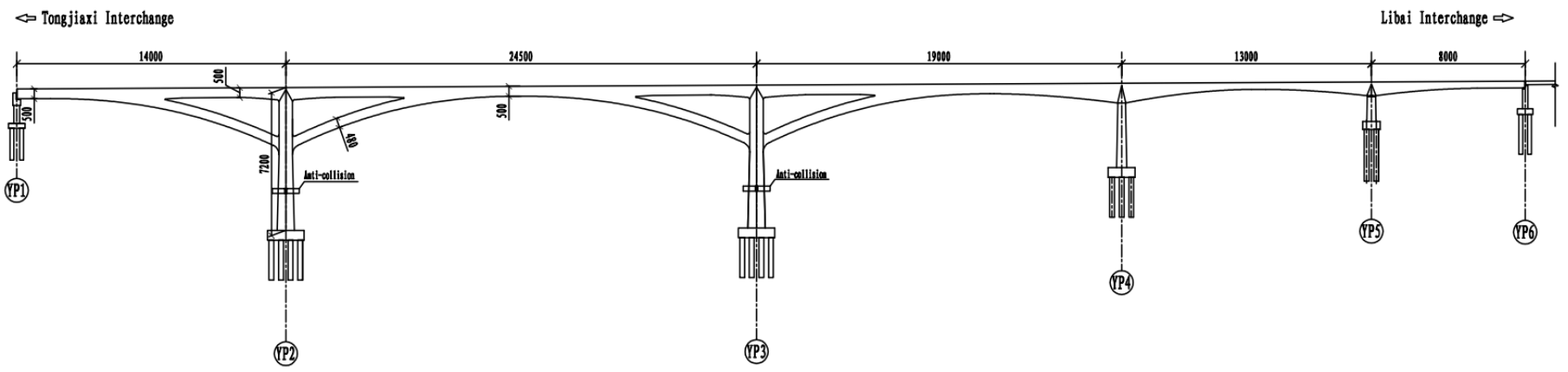

Figure 3. General layout of Lijia Jialingjiang Bridge (unit: cm) 


\section{IMPACTS OF TEMPORARY CABLES ON UPPER BEAM}

This paper explores the true function of the cables on the upper beam through comparative calculations. Figure 4 shows the stress states on the upper and lower edges of the upper beam before the closure of upper beam and lower arch, without any temporary cable on the upper beam during cantilever casting. Due to the existence of pre-stressed steel cables on the upper beam, all sections of the upper beam are fully compressed, even without any temporary cable to pull the upper beam. Therefore, the effect of unfavorable stress was neglected in the application of temporary cables. Figure 5 provides the stress states on the upper and lower edges of the upper beam with two or three temporary cables.

According to Article 5.2.2 of The Specifications for Design of Highway Reinforced Concrete and Pre-Stressed Concrete Bridges and Culverts (JTG 3362-2018), the bending capacity of rectangular section can be computed by:

$$
\begin{aligned}
& \gamma_{0} M_{d} \leq f_{c d} b x\left(h_{0}-\frac{x}{2}\right) \\
& +f_{s d}^{\prime} A_{s}^{\prime}\left(h_{0}-a_{s}^{\prime}\right)+\left(f_{p d}^{\prime}-\sigma_{p 0}^{\prime}\right) A_{p}^{\prime}\left(h_{0}-a_{p}^{\prime}\right)
\end{aligned}
$$

where, $h_{0}$ is the effective height of the section. The above formula shows that the bending capacity of the positive section of the upper beam has a strong positive correlation with the height of the main beam.

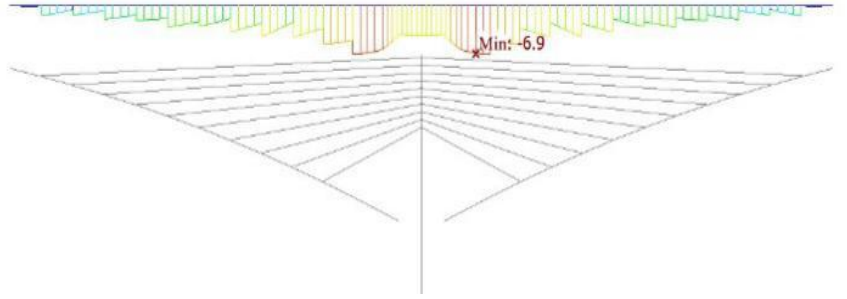

(a) Upper edge

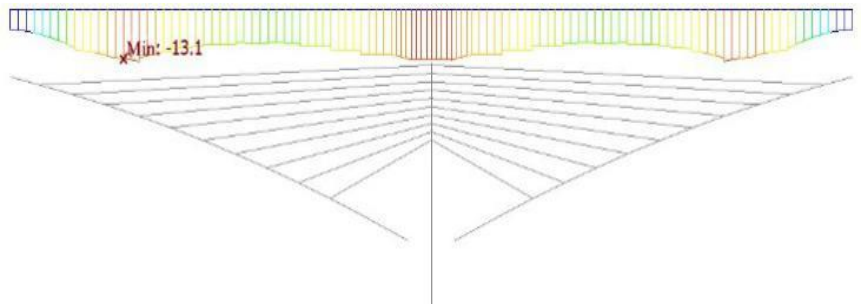

(b) Lower edge

Figure 4. The stress states on the upper and lower edges of the upper beam without temporary cables (unit: $\mathrm{MPa}$ )

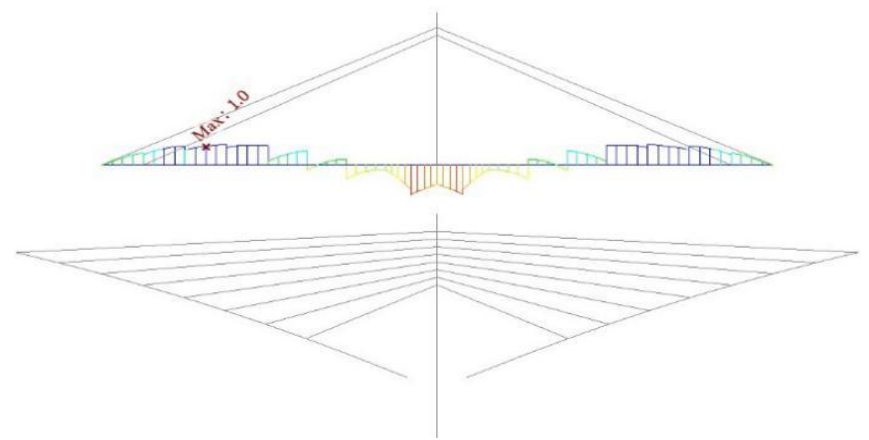

(a) Two temporary cables
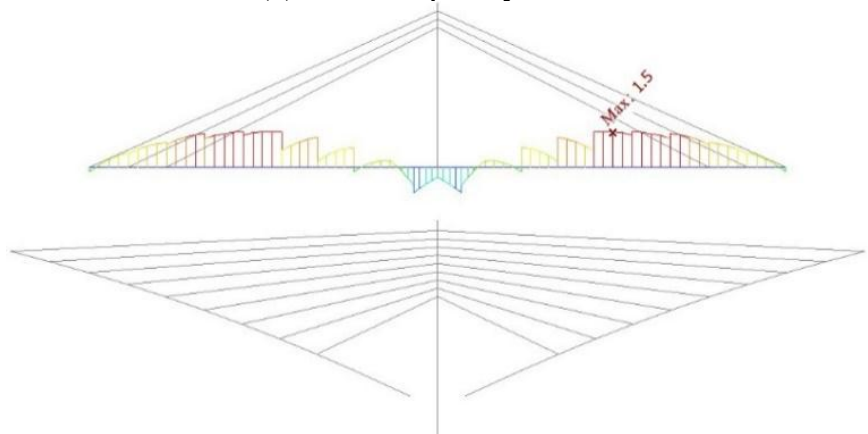

(b) Three temporary cables

Figure 5. The stress states on the upper and lower edges of the upper beam with temporary cables (unit: MPa)

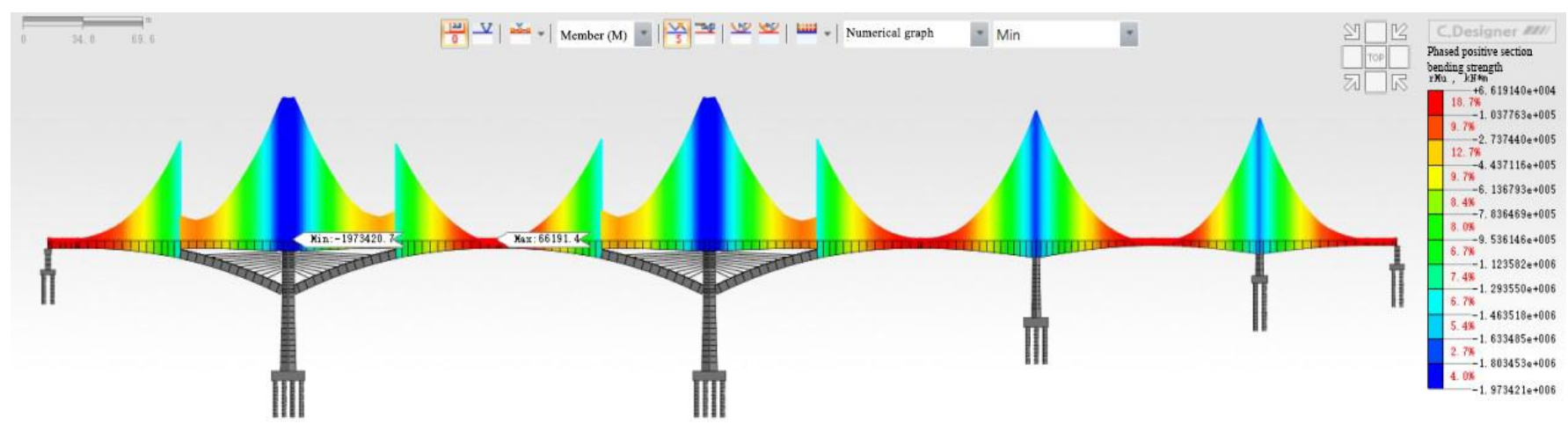

Figure 6. The envelope diagram of the minimum bending moment (unit: $\mathrm{kN} \cdot \mathrm{m}$ )

The envelope diagram of the minimum bending moment of Lijia Jialingjiang Bridge is displayed in Figure 6, where the height at the root of the upper beam and the height of the main beam at the beam-arch joint were 6.5 and $10.612 \mathrm{~m}$, respectively. For the long-span span beam-arch composite rigid frame bridge, it is obvious that the bending capacity of the positive section is controlled by the root section of the upper beam, which is relatively short. With the growing length of the open web, the difference between the root section of the upper beam and the beam-arch joint gradually widened in terms of the maximum negative moment.

Table 1 records the internal force variations in root section of the upper beam, in the presence of one to four temporary cables. It can be seen that the tensioning and removal of the four cables caused the bending moment and axial force in root section of the upper beam to increase by $M_{\text {Increment }}=+26.21 \times 10^{4} \mathrm{kN} . \mathrm{m} \quad$ and $\quad N_{\text {Increment }}=+1.54 \times 10^{4} \mathrm{kN}$, respectively. 
Table 1. Internal force variations in root section of the upper beam with one to four temporary cables

\begin{tabular}{ccc}
\hline Working conditions & $\begin{array}{c}\text { Bending moment } \\
\text { increment }(\mathbf{k N} \cdot \mathbf{m})\end{array}$ & $\begin{array}{c}\text { Axial force } \\
\text { increment }(\mathbf{k N})\end{array}$ \\
\hline $\begin{array}{c}\text { Tensioning } \\
\text { temporary cable } 1 \#\end{array}$ & $+12.13 \times 10^{4}$ & $-0.63 \times 10^{4}$ \\
$\begin{array}{c}\text { Tensioning } \\
\text { temporary cable } 2 \#\end{array}$ & $+12.42 \times 10^{4}$ & $-0.61 \times 10^{4}$ \\
$\begin{array}{c}\text { Tensioning } \\
\text { temporary cable 3\# } \\
\text { Tensioning }\end{array}$ & $+12.54 \times 10^{4}$ & $-0.59 \times 10^{4}$ \\
$\begin{array}{c}\text { temporary cable 4\# } \\
\text { Removing four } \\
\text { temporary cables at } \\
\text { closure } \\
\text { Total }\end{array}$ & $+12.63 \times 10^{4}$ & $-0.56 \times 10^{4}$ \\
& $-23.51 \times 10^{4}$ & $+3.93 \times 10^{4}$ \\
\hline
\end{tabular}

In the completion state, the cantilever root is tensioned on the upper edge and compressed on the lower edge. The compressive stress on the upper edge increased by $\Delta \sigma_{M}=-$ $2.85 \mathrm{MPa}$ and $\Delta \sigma_{N}=+0.42 \mathrm{MPa}$, under the action of $M_{\text {Increment }}$ and $N_{\text {Increment }}$, respectively. In other words, the upper edge of the cantilever root faced an additional compressive stress of $\Delta \sigma_{\mathrm{M}+\mathrm{N}}=-2.43 \mathrm{MPa}$ on the upper edge, owing to the growth in bending moment and axial force.

The above results show that the negative impact from the changing axial force on bearing capacity is completely outshined by the positive impact from the changing bending moment; the bending moment increment accounts for $26.67 \%$ in the bending moment at the completion state:

$$
\begin{aligned}
& \eta_{\text {Bending moment }}=\frac{M_{\text {Increment }}}{M_{\text {Completion }}} \\
& =\left|\frac{+26.21 \times 10^{4} k N . m}{-98.28 \times 10^{4} k N . m}\right|=26.67 \%
\end{aligned}
$$

It can also be seen that the shear force increment mainly brings the change of section shear stress; the shear capacity of the section can be effectively enhanced by deploying bent-up bars, stirrups and vertical pre-stressing. Thus, the shear capacity is not a common controller of the safety of beam structure. This paper mainly studies the effects of temporary measures on the bending capacity of the upper beam, without paying much attention to shear capacity. (Note: the tensile stress is considered positive and the compressive stress, negative.)

In summary, no unfavorable stress will occur on the upper beam, if no temporary cable is tensioned for upper beam construction; otherwise, the lower edge of the section near the temporary cable will face a tensile strength. With the growing length of the open web, the control section of the bending capacity of the positive section gradually moves from the beam-arch joint to the root section of the upper beam in the beam-arch composite rigid frame bridge. The unfavorable bending moment of the root section of the upper beam at the completion stage can be effectively suppressed by reasonably tensioning temporary cables on the upper beam.

\section{CABLE FORCE OPTIMIZATION OF TEMPORARY CABLES ON UPPER BEAM}

The previous analysis shows that, the bending capacity of the bridge structure is positively correlated with the increment of positive bending moment on the root section of the upper beam. Therefore, the cable force optimization on upper beam aims to maximize the increment of positive bending moment on the root section of the upper beam by tensioning temporary cables, provided that the tensile stress on the upper beam is not greater than the designed tensile strength of concrete and that the cable forces of all temporary cables are uniform.

The optimization function can be defined as $f(x)=\max \left\{\Delta M_{y}^{i}\right\}$, i.e. maximizing the increment of positive bending moment on the root section of the upper beam under every combination of cable forces.

The first constraint is that the maximum tensile stress on the lower edge of the upper beam must be smaller than the designed tensile strength of concrete.

The second constraint is that the cable forces of all temporary cables are uniform, with a small variation coefficient.

$$
\begin{cases}\max & f(x)=\max \left\{\Delta M_{y}^{i}\right\} \\ \text { s.t. } & {\left[\sigma_{j}\right]_{\max } \leq f_{t d}} \\ \text { s.t. } & \mathrm{cv} \leq \Delta\end{cases}
$$

where, $\left[\sigma_{j}\right]_{\max }$ is the maximum control tensile stress on the lower edge of the upper beam after the tensioning of the $\mathrm{j}$-th cable; $f_{t d}=1.96 \mathrm{MPa}$ is the designed tensile strength of concrete; $\Delta$ is the threshold of the variation coefficient of cable forces.

In this paper, the cable forces are optimized under 12 groups of constraints (Figure 6). Four temporary cables are arranged in Groups 1-4, five in Groups 5-8, and six in Groups 9-12.

Groups 1, 5 and 9 optimize the cable forces by tensioning each temporary cable to the tensile stress on the lower edge of the upper beam $\left[\sigma_{j}\right]_{\max }=1.96 \mathrm{MPa}($ Method 1$)$;

Groups 2, 6 and 10 optimize the cable forces by tensioning the $\mathrm{j}$-th temporary cable to the tensile stress on the lower edge of the upper beam $\left[\sigma_{j}\right]_{\text {max }}=\frac{j}{n} \cdot f_{t d}($ Method 2$)$;

Groups 3, 7 and 11 optimize the cable forces by tensioning the temporary cables in a manner that the differences $\Delta\left[\sigma_{i}\right]$ between the tensile force $\left[\sigma_{j+1}\right]_{\max }$ of the $\mathrm{j}+1$-th cable and that $\left[\sigma_{j}\right]_{\text {max }}$ of the $\mathrm{j}$-th cable form an ascending arithmetic sequence (Method 3);

Groups 4, 8 and 12 optimize the cable forces by tensioning the temporary cables in a manner that the differences $\Delta\left[\sigma_{i}\right]$ between the tensile force $\left[\sigma_{j+1}\right]_{\max }$ of the $\mathrm{j}+1-$ th cable and that $\left[\sigma_{j}\right]_{\text {max }}$ of the $\mathrm{j}$-th cable form a descending arithmetic sequence (Method 4).

The cable force optimization results of the four methods are compared in Figure 7 below.

As shown in Figure 7, when the number of temporary cables is the same, there is no great difference between the increments of positive bending moment $\Delta M_{y}$ obtained by the four methods. The value of $\Delta M_{y}$ increased with the number of temporary cables. Judging by the law of variation coefficient, Method 2 was found to output the most uniform cable forces and a high increment of positive bending moment $\Delta M_{y}$.

In this way, a practical constraint was identified for cable force optimization of temporary cables on the upper beam in beam-arch composite rigid frame bridge: tensioning the $\mathrm{j}$-th temporary cable to the tensile stress on the lower edge of the upper beam (Method 2). This method can ensure the uniformity of cable forces and cause a significant growth in the positive bending moment on the root section of the upper beam. 


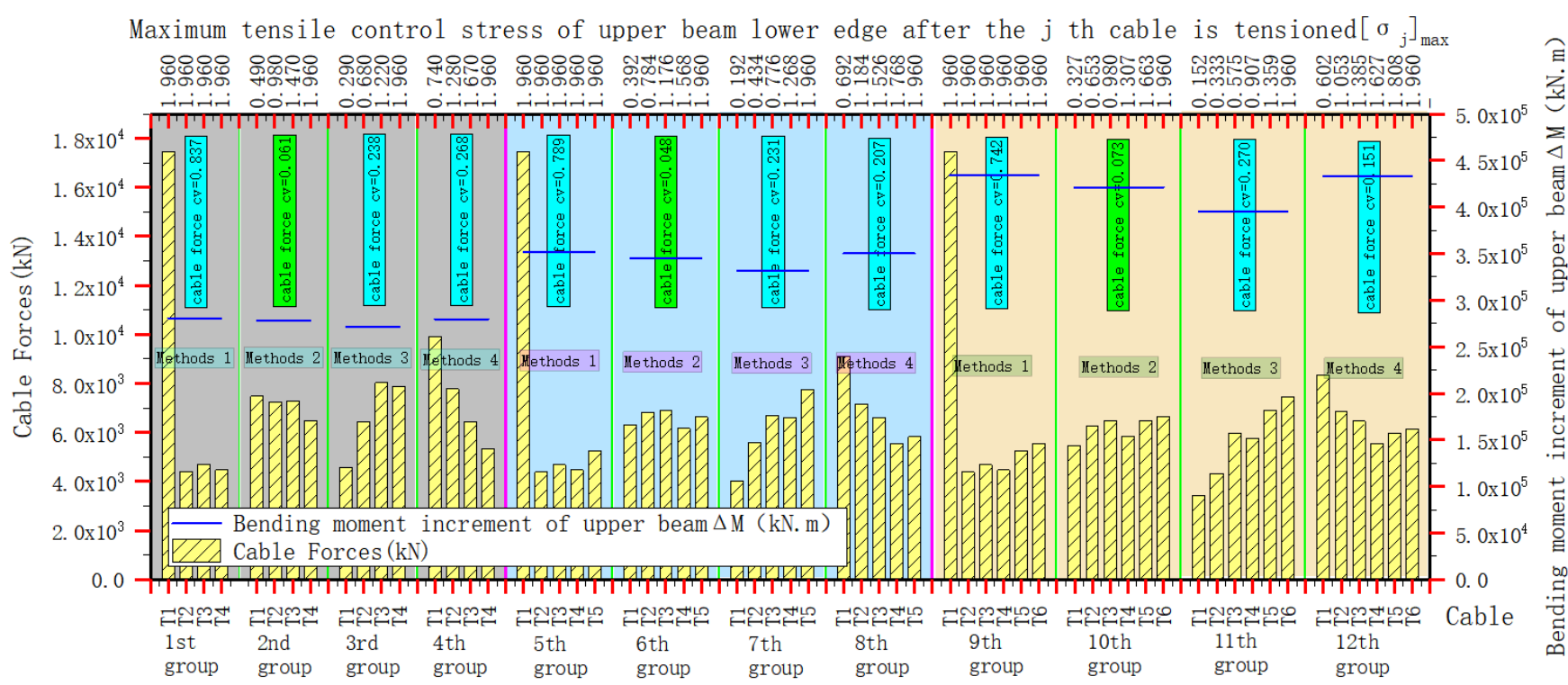

Figure 7. Optimization results of the four methods on the cable forces of the upper beam

\section{OPTIMIZATION OF THE NUMBER OF TEMPORARY CABLES ON THE UPPER BEAM}

Under the constraint of Method 2, the number of temporary cables on the upper beam was optimized through comparative analysis. A total of 78 working conditions of cable forces are listed in Table 2. Figure 8 shows the increments of positive bending moments on root section of the upper beam under the 78 working conditions

Table 2. The 78 working conditions of cable forces and their variation coefficients

\begin{tabular}{ccccccc}
\hline $\begin{array}{c}\text { Number of } \\
\text { cables }\end{array}$ & $\begin{array}{c}\text { Total number of } \\
\text { working conditions }\end{array}$ & $\begin{array}{c}\text { Node number of cables } \\
\text { being tensioned }\end{array}$ & $\begin{array}{c}\text { Node } \\
\text { interval }\end{array}$ & Working conditions & $\begin{array}{c}\text { Maximum variation } \\
\text { coefficient }\end{array}$ \\
\hline 1 & 12 & $\mathrm{Ni}$ & $\mathrm{i} \in[1,12]$ & Working condition 1-1 Working condition 1-12 & $/$ \\
2 & 11 & $\mathrm{Ni} \sim \mathrm{Ni}+1$ & $\mathrm{i} \in[1,11]$ & Working condition 2-1 Working condition 2-11 & 0.149 \\
3 & 10 & $\mathrm{Ni} \sim \mathrm{Ni}+2$ & $\mathrm{i} \in[1,10]$ & Working condition 3-1 Working condition 3-10 & 0.170 \\
4 & 9 & $\mathrm{Ni} \sim \mathrm{Ni}+3$ & $\mathrm{i} \in[1,9]$ & Working condition 4-1 Working condition 4-9 & 0.239 \\
5 & 8 & $\mathrm{Ni} \sim \mathrm{Ni}+4$ & $\mathrm{i} \in[1,8]$ & Working condition 5-1 Working condition 5-8 & 0.237 \\
6 & 7 & $\mathrm{Ni} \sim \mathrm{Ni}+5$ & $\mathrm{i} \in[1,7]$ & Working condition 6-1 Working condition 6-7 & 0.277 \\
7 & 6 & $\mathrm{Ni} \sim \mathrm{Ni}+6$ & $\mathrm{i} \in[1,6]$ & Working condition 7-1 Working condition 7-6 & 0.298 \\
8 & 5 & $\mathrm{Ni} \sim \mathrm{Ni}+7$ & $\mathrm{i} \in[1,5]$ & Working condition 8-1 Working condition $8-5$ & 0.319 \\
9 & 4 & $\mathrm{Ni} \sim \mathrm{Ni}+8$ & $\mathrm{i} \in[1,4]$ & Working condition 9-1 Working condition 9-4 & 0.329 \\
10 & 3 & $\mathrm{Ni} \sim \mathrm{Ni}+9$ & $\mathrm{i} \in[1,3]$ & Working condition 10-1 Working condition 10-3 & 0.365 \\
11 & 2 & $\mathrm{Ni} \sim \mathrm{Ni}+10$ & $\mathrm{i} \in[1,2]$ & Working condition 11-1 Working condition 11-2 & 0.336 \\
12 & 1 & $\mathrm{Ni} \sim \mathrm{Ni}+11$ & $\mathrm{i}=1$ & Working condition 12-1 & 0.339 \\
\hline
\end{tabular}

Note: Node numbers are given in Figure 8.

Five results can be drawn from Table 2 and Figure 8:

(1) The increment of positive bending moment $\Delta M_{y}$ on root section of the upper beam gradually increased, as the temporary cable approached the beam-arch junction.

(2) With the growth in the number of temporary cables, the increment of positive bending moment $\Delta M_{y}$ gradually increased on root section of the upper beam; once the number of temporary cables surpassed 7 , the maximum $\Delta M_{y}$ remained unchanged.

(3) The maximum $\Delta M_{y}=+5.60 \times 10^{5} \mathrm{kN} \cdot \mathrm{m}$, accounting for $56.98 \%$ in the bending moment at the completion state:

$$
\eta_{\text {Max }}=\frac{\Delta M_{\mathrm{y}}}{M_{\text {Completion }}}=\left|\frac{+56.0 \times 10^{4} k N . m}{-98.28 \times 10^{4} k N . m}\right|=56.98 \% \text {. }
$$

Considering the actual condition of the bridge and the structural complexity of beam-arch junction, it is advised to avoid tensioning the temporary cables at nodes 11 and 12, and to reduce the construction risk by minimizing the number of temporary cables. Hence, the cable layout of Working conditions 5-6 is the optimal arrangement. In this case, $\Delta M_{y}=+3.45 \times 10^{5} \mathrm{kN} \cdot \mathrm{m}$, accounting for $35.10 \%$ in the bending moment at the completion state:

$$
\eta_{\text {optimal }}=\frac{\Delta M_{\mathrm{y}}}{M_{\text {Completion }}}=\left|\frac{+34.5 \times 10^{4} k N . m}{-98.28 \times 10^{4} k N . m}\right|=35.10 \%
$$

(4) The temporary cables can greatly improve the internal force distribution in the upper beam.

(5) The variation coefficient of cable forces gradually increased with the number of temporary cables. Under all working conditions, the maximum variation coefficient of 
cable forces was merely 0.365. Overall, the cable force exhibited a gradual and uniform growth with the serial number of the cables. The cable forces belong to the uniform ideal state, indicating that Method 2 is a simple and practical method for cable force optimization.

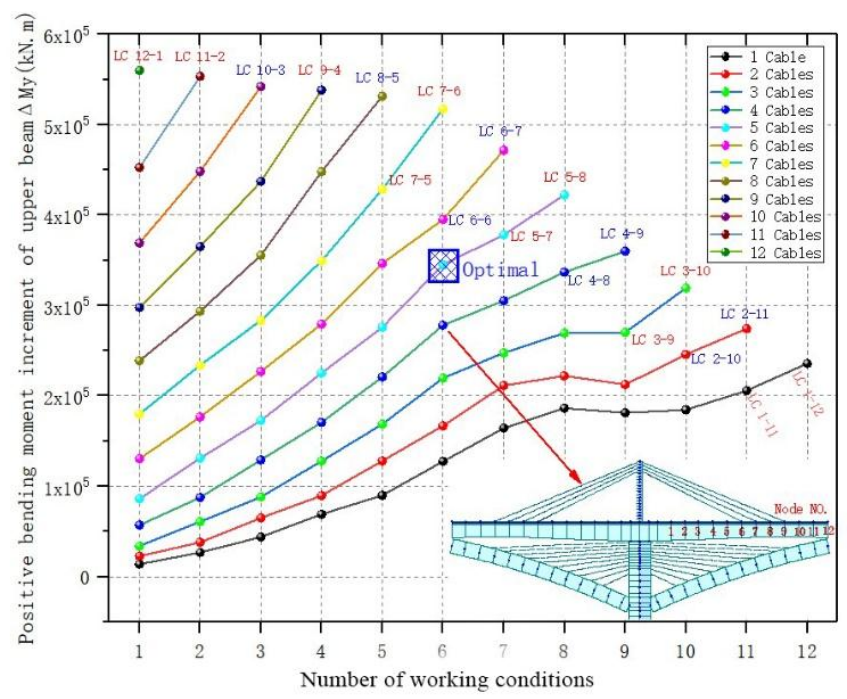

Figure 8. The increments of positive bending moments on root section of the upper beam under the 78 working conditions

\section{CONCLUSIONS}

For the safety of beam-arch composite rigid frame bridge, this paper optimizes the layout of temporary cables on the upper beam on the finite-element software midas Civil. A total of 78 different layouts of temporary cables were compared in terms of their influence over the positive bending moment on the root section of the upper beam. The following conclusions were drawn from the comparative analysis:

(1) The essential function of the temporary cables on the upper beam is to reduce the negative bending moment on the root section of the upper beam at the completion state, thereby enhancing the structural safety.

(2) A practical constraint was identified for cable force optimization of temporary cables on the upper beam in beamarch composite rigid frame bridge: tensioning the $\mathrm{j}$-th temporary cable to the tensile stress on the lower edge of the upper beam (Method 2). This method can ensure the uniformity of cable forces and cause a significant growth in the positive bending moment on the root section of the upper beam.

(3) Under the action of the temporary cables on the upper beam, the maximum and optimal increments of positive bending moment account for $56.98 \%$ and $35.10 \%$ in the bending moment at the completion state, respectively. This means the temporary cables can effectively reduce the negative bending moment on the root section of the upper beam at the completion state, and bolster the bearing capacity and safety of the structure.

(4) The bearing capacity on the positive section of the upper beam increases, as temporary cable approaches the beam-arch junction.

(5) Once the number of temporary cables surpassed 7, the maximum increment of positive bending moment of the upper beam $\Delta M_{y}$ remained unchanged. Considering factors like construction risks, it is recommended to tension five temporary cables.

\section{ACKNOWLEDGMENTS}

This work was supported by Chongqing Science and Technology Bureau (Grant No.: cstc2018jscx-mszd0430) and China State Construction (Grant No.: CSCEC-2018-Z-17).

\section{REFERENCES}

[1] Zhang, X.S., Liang, N.Y., Lu, X.H., Gu, A.B., Shan, J.D. (2019). Optimization method for solving the reasonable arch axis of long-span CFST arch bridges. Advances in Civil Engineering, https://doi.org/10.1155/2019/7235656

[2] Salonga, J., Gauvreau, P. (2014). Comparative study of the proportions, form, and efficiency of concrete arch bridges. Journal of Bridge Engineering, 19(3): 04013010. https://doi.org/10.1061/(ASCE)BE.1943-5592.0000537

[3] Peng, Y.C., Zhou, S.X., Xu, L.Q. (2017). Economic comparison of structural design parameters of prestressed concrete open-web continuous rigid frame bridges. Journal of China \& Foreign Highway, 37(6): 151-155. https://doi.org/10.14048/j.issn.16712579.2017.06.032

[4] Huang, K.Q., Peng, X.M. (2011). Analysis of mechanical behavior of a presressed concrete open-web continuous rigid-frame bridge in construction process. Bridge Construction, (3): 40-43.

[5] Liao, W.Y., Ni, Y.Q., Zheng, G. (2012). Tension force and structural parameter identification of bridge cables. Advances in Structural Engineering, 15(6): 983-995. https://doi.org/10.1260/1369-4332.15.6.983

[6] Liang, P., Xiao, R.C., Zhang, X.S. (2003). Practical method of optimization of cable tensions for cable-stayed bridges. Journal of Tongji University (Natural Science), (11): 1270-1274.

[7] Qi, L.K., Chen, Z.L., Song, J.Y., Liu, Z.S. (2007). Optimization of cable forces before joining during cantilever construction for arch bridge. Journal of Highway and Transportation Research and Development, (7): 82-85.

[8] Hassan, M.M., Nassef, A.O., El Damatty, A.A. (2012). Determination of optimum post-tensioning cable forces of cable-stayed bridges. Engineering Structures, 44: 248259. https://doi.org/10.1016/j.engstruct.2012.06.009

[9] Martins, A.M.B., Simoes, L.M.C., Negrao, J.H.J.O. (2015). Cable stretching force optimization of concrete cable-stayed bridges including construction stages and time-dependent effects. Structural and Multidisciplinary Optimization, 51(3): 757-772. https://doi.org/10.1007/s00158-014-1153-4

[10] He, W., Zhou, W.G., Chen, J.C. (2015). Study of optimization of fastening stay forces for arch bridge constructed by cantilever casting. Bridge Construction, 45(3): 32-36.

[11] Hu, D.L., Chen, D.S., Zhao, X.Y., Gong, J.P., Li, Y. (2016). Construction control of cantilever casting of long span reinforced concrete arch bridge. Journal of Traffic and Transportation Engineering, 16(1): 25-36. https://doi.org/10.19818/j.cnki.1671-1637.2016.01.004 
[12] Zarbaf, S.E.H.A.M., Norouzi, M., Allemang, R.J. (2017). Stay cable tension estimation of cable-stayed bridges using genetic algorithm and particle swarm optimization. Journal of Bridge Engineering, 22(10): 05017008. https://doi.org/10.1061/(ASCE)BE.1943-5592.0001130

[13] Gao, Q., Yang, M.G., Qiao, J.D. (2017). A multiparameter optimization technique for prestressed concrete cable-stayed bridges considering prestress in girder. Structural Engineering and Mechanics, 64(5): 567-577. https://doi.org/10.12989/sem.2017.64.5.567

[14] Ha, M.H., Vu, Q.A., Truong,V.H. (2018). Optimum design of stay cables of steel cable-stayed bridges using nonlinear inelastic analysis and genetic algorithm. Structures, 16: 288-302.
[15] Song, C., Xiao, R., Sun, B. (2018). Optimization of cable pre-tension forces in long-span cable-stayed bridges considering the counterweight. Engineering Structures, 172: 919-928. https://doi.org/10.1016/j.engstruct.2018.06.061

[16] Arellano, H., Tolentino, D., Gómez, R. (2019). Optimum criss crossing cables in multi-span cable-stayed bridges using genetic algorithms. KSCE Journal of Civil Engineering, 23(2): 719-728. https://doi.org/10.1007/s12205-018-5736-2

[17] Dai, J., Qin, F.J., Di, J., Chen, Y.R. (2019). Review on cable force optimization method for cable-stayed bridge in completed bridge state. China Journal of Highway and Transport, 32(5): 17-37. https://doi.org/10.19721/j.cnki.1001-7372.2019.05.002 